\title{
The Incidence of Post Phacoemulsification Surgery Induced Dry Eye Disease in Upper Egypt
}

\author{
Mohamed Ateto Hamed (D)', Ahmed Hasan Aldghaimy ${ }^{2}$, Nouran Saleh Mohamed ${ }^{3}$, Ahmed Ali Amer ${ }^{2}$ \\ 'Ophthalmology Department, Luxor University, Luxor, Egypt; ${ }^{2}$ Ophthalmology Department, South Valley University, Qena, Egypt; ${ }^{3}$ Ophthalmology \\ Department, South Valley University, Luxor, Egypt \\ Correspondence: Mohamed Ateto Hamed, Email dr_m_ateto@yahoo.com
}

\begin{abstract}
Background: Dry eye is described as a multifactorial disorder of the tear film that occurs due to excessive tear evaporation or tears insufficiency, and so leads to ocular discomfort sensation and ocular tissue damage with time.

Objective: To assess the incidence of dry eye disease after uncomplicated phacoemulsification surgery in patients with no pre-existed dry eye.

Patients and Methods: This hospital-based cross-sectional study was conducted to assess the incidence of dry eye at 100 eyes of 100 patients who underwent uncomplicated phacoemulsification surgery, with age more than 45 years old. It is measured by dry eye tests Schirmer 1 and tear break up time.

Results: This study showed that $22 \%$ of the patients who underwent uncomplicated phacoemulsification surgery suffered from dry eye with significant results at 1 st week post-operative that improved over time.

Conclusion: There was a statistically significant drop in the results of the Schirmer test 1 and TBUT post phacoemulsification surgery, but with no clinical significance as they still at the normal range. The tear film assessment results at the 1 st week postoperative were out of the normal range with TBUT and were borderline with ST1 in 22\% of the patients. These results improved over time to return to the normal values within 12 weeks postoperatively.
\end{abstract}

Keywords: dry eye disease, uncomplicated phacoemulsification surgery

\section{Introduction}

Dry eye disease is a disorder of the tear film, that occurs due to excessive tear evaporation or tears insufficiency, and so leads to ocular surface damage. It is accompanied by ocular discomfort, itching, burning, lacrimation, blurring of vision and foreign body sensation. ${ }^{1}$ Dry eye disease is a disease caused by many factors has a high prevalence over the past few years due to overusing contact lens, computers and a greater number of laser surgeries. It is also associated with systemic diseases as 'diabetes mellitus, autoimmune diseases, and hypertension', ocular diseases and eyelid abnormalities, some drugs such as topical eye drops that contain preservatives, antihistaminic drugs, anticholinergic drugs, contraceptive pills. ${ }^{2,3}$ Dry eyes are one of the major factors affecting quality of life. It interferes with everyday life activities, impacts on visual function especially, reading, driving, and using a computer. Sometimes it is associated with mood changes and a decrease in workplace productivity. ${ }^{4,5}$ Despite the importance of cataract surgeries for vision improvement, many patients still unsatisfied due to developing postoperative dry eye symptoms. This disorder occurs after extra-capsular cataract extraction surgery, due to its large incision which decreases corneal sensitivity and sometimes damages the cornea.

Various factors may influence the ocular surface environment and the extent to which dry eyes occur after cataract surgery. The most important of which is the desensitization of the cornea resulting from the incision. ${ }^{6}$ Other Factors that are accused for occurrence of post-cataract surgery dry eye symptoms include postoperative use of combined antibioticsteroid eye drops or ointment, irregularities of corneal surface at the incision site causing prolongation of tear break up, decrease goblet cell conjunctival population near the incision reducing the mucin production, diminished corneal 
sensation secondary to surgical incision which interrupts the cornea-lacrimal gland loop reducing, some sort of surgically induced ocular inflammation that affects the tear production and exposure to light from the surgical microscope. ${ }^{7-9}$

There are few reports that refer to the incidence of dry eye symptoms after uncomplicated cataract phacoemulsification in patients without prior dry eye syndrome. ${ }^{6}$ Therefore, this study aims to detect incidence of post Phacoemulsification surgery induced dry eye disease in upper Egypt.

\section{Patients and Methods}

\section{Ethical Approval}

The research protocol was designed in accordance with the Declaration of Helsinki and the Medical Research Council's Guidelines for Ethical Biomedical Research on Human Subjects. The institutional ethics committee of Qena faculty of medicine, South Valley University, Egypt, approved the research. Written informed consent was obtained from all patients prior to their enrollment.

-Type of Study: This is a prospective study.

-Study website: This study was conducted at Qena University Hospital.

-Study date and duration: This study was conducted between June 2021 and November 2021.

-Study Objects: this study included 100 cataract patients, with age above 45 years old who underwent uncomplicated phacoemulsification surgery. Povidone iodine 5\% was used to sterilize the ocular surfaces. Sterile adhesive was used to isolate the globe. Care is made not to use tight speculum as it may damage the fornices. $2.8 \mathrm{~mm}$ clear corneal main incision and two side ports are used for surgery. Manipulations to the conjunctiva and limbus by the forceps is minimized as possible to avoid damage to the goblet cells. Postoperative regimen include moxifloxacin eye drops 5 times daily and prednisolone acetate $1 \%$ eye drops 5 times daily for one week.

\section{Inclusion Criteria}

- Cataract patients.

- Cases within age $>45$ years old.

\section{Exclusion Criteria}

- Patients with pre-existing dry eye: They are not included in the study from the beginning.

- Patients with ocular surface diseases and eyelid abnormality.

- Patients receive ocular or systemic medications, that interfere with tear film production and stability (eg topical eye drops that contain preservatives, antihistaminic drugs, anticholinergic drugs, contraceptive pills).

- patients with ocular hypertension (OHTN), rheumatoid arthritis.

- Patients underwent previous ocular surgeries that interfere with tears instability or production (eg refractive surgery, keratoplasty, eyelid surgeries, pterygium excision).

- Patients with a history of trauma, chemical burns and excessive use of contact lenses (due to destruction of the conjunctiva and goblet cells including decreased sensitivity of the cornea).

- Patients with a history of trauma, chemical burns, excessive use of contact lenses (because of the destruction of the conjunctiva and goblet cells including a reduction in corneal sensitivity).

\section{Methods}

\section{All Patients Were Subjected for Routine Preoperative Ophthalmological Examination}

- Assessment of vision by Snellen chart.

- Refraction.

- Measuring IOP.

- Slit lamp examination.

- Fundus examination by 90D lens. 
- Tear film function was assessed at all cases preoperatively and at 1 st week, 4 th week and 12 th week after the surgery, by Schirmer test-1 (ST-I) and tear film break-up time (TBUT).

Schirmer Test-1: performed without using topical anesthesia, to assess the basic and reflex tear production. Filter paper $5 \mathrm{~mm}$ was bent at one end and inserted at the junction of the middle and outer third of the lower eyelid of the patient's eye on which the phacoemulsification was applied, and the examiner should not touch the cornea or eyelashes. The patients are asked to close their eyes gently and after 5 minutes the filter paper is removed and assessed how far the tears have traveled on the paper. It is considered abnormal when the level of wetting is less than 10mm. Depending upon the amount of wetting, severity of dry eye is assessed (Figure 1).

- Tears break up time: To measure this, the fluorescein is instilled into the patient's lacrimal film with a fluorescein strip moistened with saline and placed on the lower fornix. After several blinks, the patient is instructed not to blink while observing the tear film under a broad beam of cobalt blue illumination. TBUT is considered abnormal when it is under 10 seconds. Depending upon a time it was categorized as follows: (Normal $>10$ Seconds, Mild to moderate is 5 seconds $-\leq 10$ seconds, severe is $<5$ seconds). The interval between ST-1 and TBUT was at least 10 minutes (Figure 2).

\section{Data Analysis}

Statistical analysis was performed in conjunction with a PC using SPSS version 26 for windows. Frequencies, descriptive statistics, correlation, X-test, $t$-test and regression analysis were done. A probability of less than 0.05 was used as the cutoff point for all significant tests.
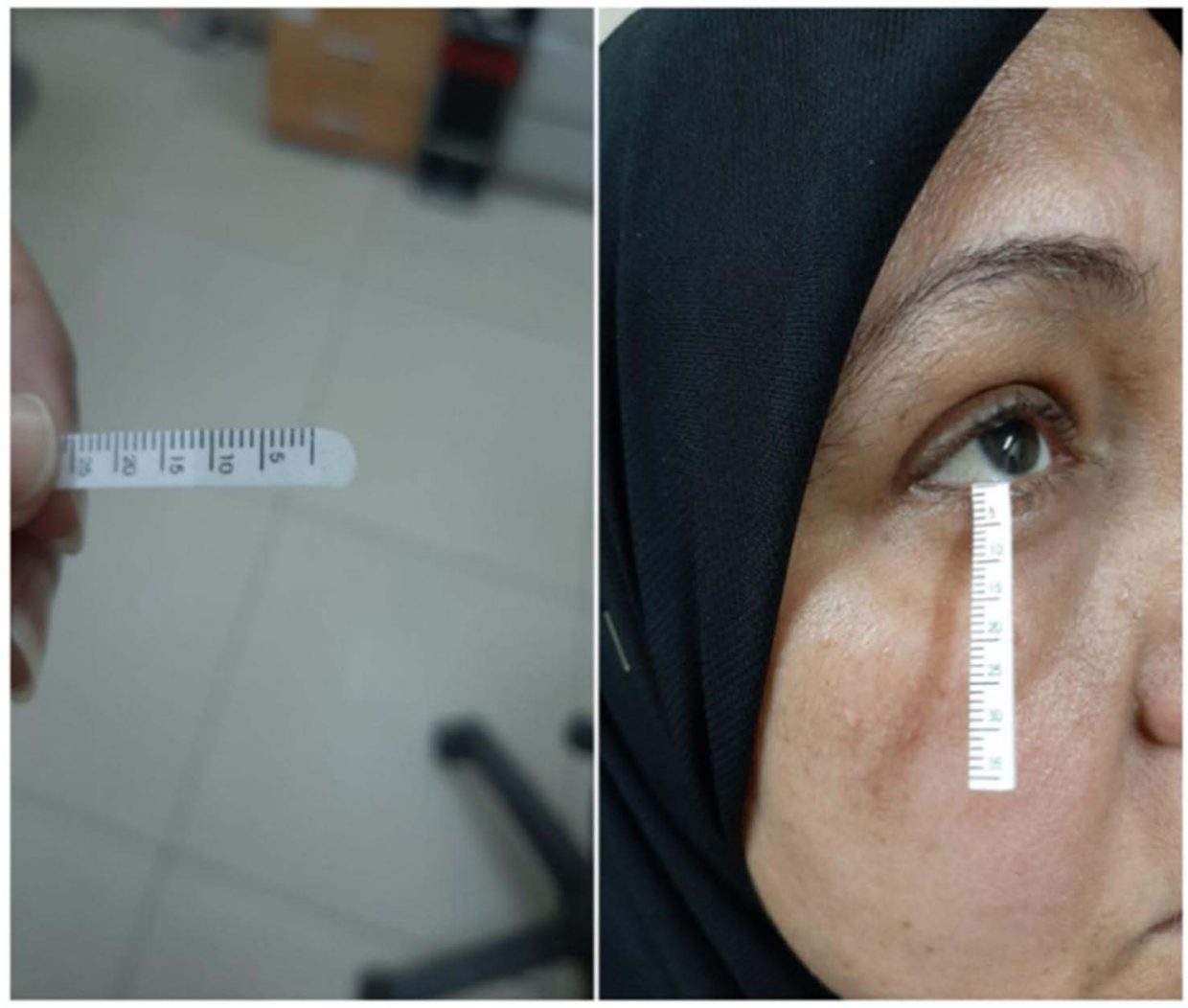

Figure I Schirmer test I at right eye of female patient that showed value of less than $15 \mathrm{~mm}$ at Ist week postoperative. 


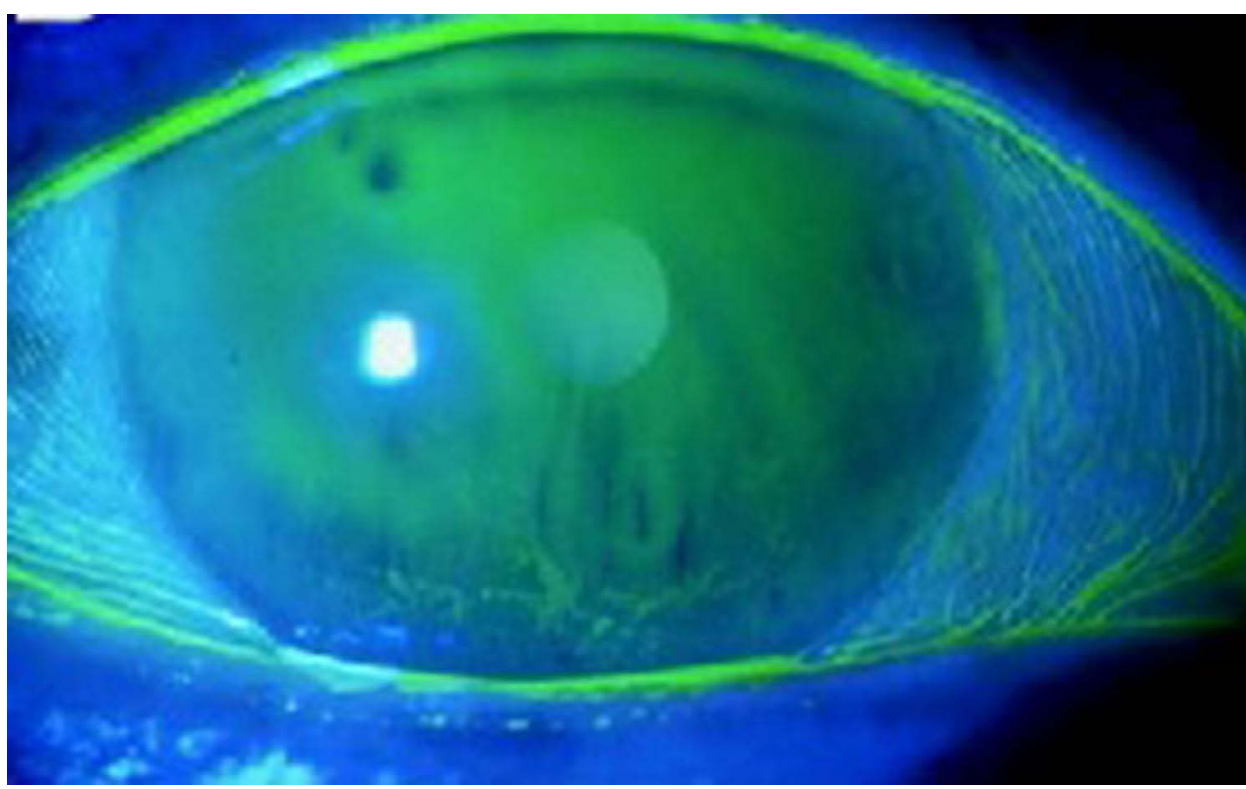

Figure 2 TBUT of right eye of male patient, that showed normal result more than 10 sec preoperative and abnormal result less than 10 sec only at Ist week postoperative.

\section{Results}

This study was conducted on 100 eyes of 100 patients distributed over (54) males and (46) females, their ages ranged from (40) to (75) with an average age of $(63.02 \pm 10.3)$ years Table 1.

Dry eye was assessed Preoperatively by the same tests ST1 and TBUT and all of them show normal values as illustrated in Table 2. The average Schirmer test 1 was 19.86 with a standard deviation (SD) $\pm 1.9 \mathrm{~mm}$. The average TBUT scores were 13.90 with a standard deviation (SD) of \pm 1.6 seconds.

The dry eye was evaluated again by ST1, TBUT postoperatively at 1st week, 4th week and 12th week then compared their results with the preoperative results and found that:

The mean value of Schirmer test I result on 1st week post-operative was $15.44 \mathrm{~mm}$ with a statistically significant difference from pre-operative assessment which was $19.86 \mathrm{~mm}$ ( $\mathrm{p}$-value $=0.001)$. On 4th week post-operative, the mean value was $17.30 \mathrm{~mm}$. On 12th week post-operative, the mean was $18.54 \mathrm{~mm}$. Both 4th week, 12th week results have

Table I Demographic Data of the Studied Population

\begin{tabular}{|c|c|}
\hline & Descriptive Statistics \\
\hline \multicolumn{2}{|l|}{ Age (years); N (\%) } \\
\hline$<55$ & $30(30.00)$ \\
\hline $55-70$ & $44(44.00)$ \\
\hline$>70$ & $26(26.00)$ \\
\hline Total & $100(100.00)$ \\
\hline Mean \pm SD & $63.02 \pm 10.3$ \\
\hline Range (Maximum - Minimum) & $(80-45)$ \\
\hline \multicolumn{2}{|l|}{ Gender; N (\%) } \\
\hline Female & $46(46.00)$ \\
\hline Male & $54(54.00)$ \\
\hline
\end{tabular}


Table 2 Pre-Operative Assessment of Eye Dryness

\begin{tabular}{|l|l|c|c|c|}
\hline & Test & Minimum & Maximum & Mean \pm SD \\
\hline I- & Schirmer test I "mm" & 17.00 & 26.00 & $19.86 \pm 1.9$ \\
\hline $2-$ & Tear film break-up time "sec". & 11.00 & 18.00 & $13.90 \pm 1.6$ \\
\hline
\end{tabular}

Table 3 Patients' Sequential Changes in Dry Eye Tests Over Time; (N=100)

\begin{tabular}{|l|c|c|c|c|c|}
\hline \multirow{2}{*}{ Test } & \multicolumn{4}{|c|}{ Mean \pm SD } & Overall \\
\cline { 2 - 5 } & $\begin{array}{c}\text { Pre- } \\
\text { Operative }\end{array}$ & $\begin{array}{c}\text { I Week Post- } \\
\text { Operative }\end{array}$ & $\begin{array}{c}\text { 4 Weeks Post- } \\
\text { Operative }\end{array}$ & $\begin{array}{c}\text { I 2 Weeks Post- } \\
\text { Operative }\end{array}$ & -value \\
\hline $\begin{array}{l}\text { Schirmer I } \\
\text { test }\end{array}$ & $19.86 \pm 1.9$ & $15.44 \pm 3.4$ & $17.30 \pm 2.5$ & $18.54 \pm 1.9$ & $<0.001$ \\
\hline TBUT & $13.90 \pm 1.6$ & $10.84 \pm 2.4$ & $12.04 \pm 1.5$ & $12.78 \pm 1.5$ & $<0.001$ \\
\hline
\end{tabular}

Note: P-value $<0.05$ is significant.

significant difference from pre-operative one, it is illustrated in Tables 3 and 4 . This pattern of mean scores shows that dry eye scores peaked at 1 week after surgery which gradually improved over 12 weeks and returned to normal values that were close to preoperative values.

The mean value of the TBUT score in the first week after surgery was 10.84 seconds with a statistically significant difference from the pre-operative assessment of 13.9 seconds $(\mathrm{P}=0.001)$. On 4th week post-operative, the mean value was 12.04 seconds. On 12th week post-operative, the mean value was 12.78 seconds. Both 4th week, 12th week results have a statistically significant difference from pre-operative one, it is illustrated in Tables 3 and 4 . This pattern of mean scores shows that dry eye scores peaked at 1 week after surgery which gradually improved over 12 weeks and returned to normal values that were close to preoperative values.

Out of (100) eyes of 100 patients; Only ${ }^{22}$ of them experienced mild to moderate dryness after surgery in the first week, according to the results of dry eye tests discussed previously. It is shown in Table 5.

In our study there was a non-significant relationship between dry eyes after surgery and the gender of the patient. ( $p$ value $>0.05$ ). It is shown in Table 6 .

Table 4 Comparison of P-values for Patients' Sequential Changes in Dry Eye Tests Over Time; (N= 100)

\begin{tabular}{|c|c|c|c|c|}
\hline & Pre-Operative & I Week & 4 Weeks & I 2 Weeks \\
\hline & & & & Schirmer test I \\
\hline \multicolumn{5}{|c|}{ Pre-operative } \\
\hline I week & 0.001 & & & \\
\hline 4 weeks & 0.001 & 0.001 & & \\
\hline 12 weeks & 0.010 & 0.001 & 0.016 & \\
\hline \multicolumn{5}{|c|}{ Tear film break-up time } \\
\hline \multicolumn{5}{|c|}{ Pre-operative } \\
\hline I week & 0.001 & & & \\
\hline 4 weeks & 0.001 & 0.001 & & \\
\hline 12 weeks & 0.002 & 0.001 & 0.042 & \\
\hline
\end{tabular}


Table 5 Frequency of Post-Operative Dry Eye

\begin{tabular}{|l|l|c|c|}
\hline \multicolumn{2}{|l|}{} & Frequency & Percent \\
\hline & Normal & 78 & 78.0 \\
\hline Dry Eye & 22 & 22.0 \\
\hline Total & 100 & 100.0 \\
\hline
\end{tabular}

Table 6 Association Between Gender and Eye Dryness

\begin{tabular}{|c|c|c|c|c|c|}
\hline & & \multicolumn{2}{|c|}{ Gender } & \multirow[t]{2}{*}{ Total } & \multirow[t]{2}{*}{ p-value } \\
\hline & & Female $N=46$ & Male $\mathbf{N}=\mathbf{5 4}$ & & \\
\hline \multirow[t]{2}{*}{ Postoperative Eye Dryness } & Normal & 34 (73.9\%) & 44 (81.5\%) & 78 (78.0\%) & \multirow[t]{2}{*}{0.780} \\
\hline & Dry Eye & $12(26.1 \%)$ & $10(18.5 \%)$ & $22(22.0 \%)$ & \\
\hline
\end{tabular}

Note: $P$-value $<0.05$ is significant.

Also, we found a statistically significant association between the incidence of dry eye after surgery and the age of patients $(\mathrm{P}=0.036)$, in which the incidence of dry eye increases with age, as shown in Table 7.

The association between patient age and dry eye assessment after phacoemulsification 1 week after surgery showed that: Schirmer 1 test results were moderately negative with age of patients $(r=-0.452$, p-value $=0.001)$. TBUT scores were slightly negatively correlated with patient age $(\mathrm{r}=-0.392$, $\mathrm{p}$-value $=0.005)$. The results are shown in Table 8 .

\section{Discussion}

The present study showed that the incidence of dry eyes after uncomplicated phacoemulsification is $22 \%$ of patients in the first week after surgery. Dry eye can often occur after different types of eye surgeries such as photorefractive keratectomy and laser-assisted in situ keratomileusis (LASIK). After LASIK, dry eyes can persist for up to 6 months or longer at $20 \%{ }^{2}$ There is lack of measuring symptoms and signs of dry eye following cataract surgery.

Also, it has been widely observed that cataract surgery negatively affects the state of the tear film in the early postoperative period, leading to the development of dry eye in various studies. ${ }^{6,10}$ In our study we found that age has a significant association with the incidence of dry eyes after phacoemulsification. Also, Dodia et al reported that cataract surgery after phacoemulsification showed an association of dry eyes with advancing age ( $>65$ years). ${ }^{11}$

Table 7 Association of Age and Postoperative Dry Eye

\begin{tabular}{|c|c|c|c|c|c|c|}
\hline \multicolumn{2}{|c|}{ Patients' Age } & \multirow{2}{*}{$\frac{\text { Normal Eye }}{28}$} & \multirow{2}{*}{$\frac{\text { Dry Eye }}{2}$} & \multirow{2}{*}{$\begin{array}{c}\text { Total } \\
30\end{array}$} & \multirow{2}{*}{$\begin{array}{c}\text { Chi-Square } \\
6.66\end{array}$} & \multirow{2}{*}{$\begin{array}{c}\text { P-value } \\
0.036\end{array}$} \\
\hline$<55$ & Count & & & & & \\
\hline & $\%$ & $35.9 \%$ & $9.1 \%$ & $30.0 \%$ & & \\
\hline \multirow[t]{2}{*}{$55-70$} & Count & 36 & 8 & 44 & & \\
\hline & $\%$ & $46.2 \%$ & $36.4 \%$ & $44.0 \%$ & & \\
\hline \multirow[t]{2}{*}{$>70$} & Count & 14 & 12 & 26 & & \\
\hline & $\%$ & $17.9 \%$ & $54.5 \%$ & $26.0 \%$ & & \\
\hline \multirow[t]{2}{*}{ Total } & Count & 78 & 22 & 100 & & \\
\hline & $\%$ & $100.0 \%$ & $100.0 \%$ & $100.0 \%$ & & \\
\hline
\end{tabular}

Note: $P$-value $<0.05$ is significant. 
Table 8 Correlation Between Post Phacoemulsification Dry Eye Assessment and Patients' Age

\begin{tabular}{|l|l|l|}
\hline \multirow{2}{*}{ Test } & \multicolumn{2}{|l|}{ Patients' Age } \\
\cline { 2 - 3 } & R & p-value \\
\hline Schirmer I test & -0.452 & 0.001 \\
\hline Tear film break-up time & -0.392 & 0.005 \\
\hline
\end{tabular}

Note: $P$-value $<0.05$ is significant.

In this study there is no significant difference in the incidence of dry eyes after phacoemulsification between the sexes, and this is in contrast to other studies reporting a higher prevalence of dry eyes in females compared to males in the general population. ${ }^{12,13}$

But Dhawan et al reported post phacoemulsification cataract surgery showed non-significant association of dry eye with Gender. ${ }^{14}$ The values of St1 and TBUT test in this study at the 1st week postoperatively showed a significant deterioration from preoperative normal values, indicating the incidence of eye dryness which was at its peak then improved with time. So that the values of the tests were normal at 12 th week postoperatively with a little difference from the perioperative values. This pattern of postoperative dry eyes in our study was consistent with the findings of Barabino et al (unpublished data), who observed an occurrence of dry eyes on day 7 after surgery with rapid improvement within 30 days after surgery. ${ }^{15}$

Kasetsuwan et al also reported that the signs and symptoms of dry eyes occurred as early as 7 days after phacoemulsification and the severity pattern improved over time. ${ }^{15}$

Various factors may influence the ocular surface environment and the extent to which dry eyes occur after cataract surgery. The most important of which is the desensitization of the cornea resulting from the incision. ${ }^{6}$ Corneal nerve restoration is a possible explanation for the dry eye pattern observed in the current study. The cornea is known to be one of the most innervated organs, with about 44 corneal nerve bundles entering the cornea around central gravity, ${ }^{16}$ and larger nerve fibers extending from 9 am to $3 \mathrm{am}$. Position and cleavage to achieve a homogeneous distribution over the entire cornea. ${ }^{17}$ Therefore, they are susceptible to any damage within that region. The corneal incision created during phacoemulsification, even if it is small, can reduce the sensitivity of the cornea in the area of surgery and other areas far from the incision site. Damage to the corneal nerves may extend when longer phacoemulsification time is required to break up dense cataracts. ${ }^{18}$ Neuroinflammation can also occur after corneal incisions. Inflammatory mediators can alter the functioning of the corneal nerves and reduce corneal sensitivity. ${ }^{19}$

According to a 2007 report by the International Dry Eye Work Shop (DEWS), any abnormality in the normal corneal innervation or feedback of the lacrimal unit can reduce tear flow and blink rate, and thus cause instability, and tear film hypertolerance and dryness. ${ }^{20}$ During postoperative corneal healing, new neurite cells appear and after about 4 weeks, neuro-growth factor is released to regenerate the sub-epithelial corneal axis. ${ }^{19}$ Thus, the restoration of the corneal nerves, which enhance the corneal and lacrimal recurrent neural circuit, may explain why dry eyes appeared early after surgery and improved thereafter as observed in various tests, especially ST1, which showed a trend towards improvement in all test scores over 12 weeks.

Another possible explanation for the early occurrence and pattern of dry eyes after surgery is the use of intraoperative local anesthetics, postoperative topical eye drops, and preservatives that affect the stability of the tear film. ${ }^{10,21}$

Benzalkonium chloride, one of the most commonly used preservatives in topical eye drops, can cause tear film instability and reduce the number of mucin-expressing cells, ${ }^{22}$ resulting in and exacerbating dry eye symptoms. Therefore, stopping the use of preservative eye drops or using preservative-free topical eye drops can reduce dry eye symptoms as reported in other studies. ${ }^{23,24}$ 
Thus, the results of dry eye tests in the current study showed significant results indicating the occurrence of dry eyes early after phacoemulsification, and then gradually improved to the normal level after the fourth week after surgery, which may be due to stopping topical medications around this time.

\section{Conclusion}

There was a statistically significant decrease in the Schirmer test 1 and post-phacoemulsification results, but there was no clinical significance because they were still in the normal range.

The tear film assessment results at the 1st week post-operative, were out of the normal range at TBUT and were borderline at ST1 in 22\%of the patients. These results improved over time to return to the normal values within 12 week postoperatively. Therefore, before surgery, the patient should be informed of the possibility of early temporary symptoms of discomfort and dehydration, and if necessary, artificial tears can be prescribed in the postoperative period.

\section{Disclosure}

The authors report no conflicts of interest in this work.

\section{References}

1. Qin Y, Pan ZQ. Recent advances in dry eye: etiology, pathogenesis and management. Zhonghua Yan Ke Za Zhi. 2013;49:857-863.

2. Shoja MR, Besharati MR. Dry eye after LASIK for myopia: incidence and risk factors. Eur J Ophthalmol. 2007;17(1):1-6. doi:10.1177/ 112067210701700101

3. De Paiva CS, Chen Z, Koch D, et al. The incidence and risk factors for developing dry eye after myopic LASIK. Am J Ophthalmol. 2006;141:438-445.

4. Mertzanis P, Abetz L, Rajagopalan K, et al. The relative burden of dry eye in patients' lives: comparisons to a U.S. normative sample. Invest Ophthalmol Vis Sci. 2005;46(1):46-50. doi:10.1167/iovs.03-0915

5. Miljanović B, Dana R, Sullivan DA, Schaumberg DA. Impact of dry eye syndrome on vision-related quality of life. Am J Ophthalmol. 2007;143 (3):409-415. doi:10.1016/j.ajo.2006.11.060

6. Ram J, Gupta A, Brar G, Kaushik S, Gupta A. Outcomes of phacoemulsification in patients with dry eye. J Cataract Refract Surg. 2002;28:1386-1389.

7. Sutu C, Fukuoka H, Afshari NA. Mechanisms and management of dry eye in cataract surgery patients. Curr Opin Ophthalmol. 2016;27(1):24-30. doi:10.1097/ICU.0000000000000227

8. Cho YK, Kim MS. Dry eye after cataract surgery and associated intraoperative risk factors. Korean J Ophthalmol. 2009;23(2):65-73. doi:10.3341/ kjo.2009.23.2.65

9. Li XM, Hu L, Hu J, Wang W. Investigation of dry eye disease and analysis of the pathogenic factors in patients after cataract surgery. Cornea. 2007;26(Suppl Supplement 1):S16-S20. doi:10.1097/ICO.0b013e31812f67ca

10. Liu Z, Luo L, Zhang Z, et al. Tear film changes after phacoemulsification. Zhonghua Yan Ke Za Zhi. 2002;38:274-7.

11. Dodia K, Bapat S, Chudasama RK. Dry eye risk factors after phacoemulsification cataract surgery at a secondary care hospital. Int $J$ Health Allied Sci. 2013;2(4):242. doi:10.4103/2278-344X.126711

12. Hikichi T, Yoshida A, Fukui Y, et al. Prevalence of dry eye in Japanese eye centers. Graefes Arch Clin Exp Ophthalmol. 1995;233(9):555-558. doi:10.1007/BF00404705

13. Cetinkaya S, Mestan E, Acir NO, Cetinkaya YF, Dadaci Z, Yener HI. The course of dry eye after phacoemulsification surgery. BMC Ophthalmol. 2015;15(1):68. doi:10.1186/s12886-015-0058-3

14. Dhawan M, Kaur G, Singh SP. Dry eye after phacoemulsification. DJO. 2018;29(1):25-30. doi:10.7869/djo.372

15. Kasetsuwan N, Satitpitakul V, Changul T, Jariyakosol S. Incidence and pattern of dry eye after cataract surgery. PLoS one. $2013 ; 8(11)$ :e78657.

16. Al-Aqaba MA, Fares U, Suleman H, Lowe J, Dua HS. Architecture and distribution of human corneal nerves. Br J Ophthalmol. 2010;94 (6):784-789. doi:10.1136/bjo.2009.173799

17. Muller LJ, Vrensen GF, Pels L, Cardozo BN, Willekens B. Architecture of human corneal nerves. Invest Ophthalmol Vis Sci. 1997;38(5):985-994.

18. Sitompul R, Sancoyo GS, Hutauruk JA, Gondhowiardjo TD. Sensitivity change in cornea and tear layer due to incision difference on cataract surgery with either manual small incision cataract surgery or phacoemulsification. Cornea. 2008;Suppl 27(Suppl 1):S13-8. doi:10.1097/ ICO.0b013e 31817f29d8

19. Belmonte C, Acosta MC, Gallar J. Neural basis of sensation in intact and injured corneas. Exp Eye Res. 2004;78(3):513-525. doi:10.1016/j. exer.2003.09.023

20. Foulks GN, Lemp M, Jester J, et al. Report of the International 2007: Dry Eye Workshop (DEWS). Ocul Surf. 2007;5(2):65-204. doi:10.1016/ S1542-0124(12)70076-9

21. Roberts CW, Elie ER. Dry eye symptoms following cataract surgery. Insight. 2007;32(1):14-21.

22. Wilson WS, Duncan AJ, Jay JL. Effect of benzalkonium chloride on the stability of the precorneal tear film in rabbit and man. Br J Ophthalmol. 1975;59(11):667-669. doi:10.1136/bjo.59.11.667

23. Pisella PJ, Pouliquen P, Baudouin C. Prevalence of ocular symptoms and signs with preserved and preservative-free glaucoma medication. $\mathrm{Br}$ J Ophthalmol. 2002;86(4):418-423. doi:10.1136/bjo.86.4.418

24. Sanchez MA, Parriola-Villalobos P, Torralbo-Jimenez P, et al. The effect of preservative-free HP-Guar on dry eye after phacoemulsification: a flow cytometric study. Eye. 2010;24(8):1331-1337. doi:10.1038/eye.2010.24 


\section{Publish your work in this journal}

Clinical Ophthalmology is an international, peer-reviewed journal covering all subspecialties within ophthalmology. Key topics include: Optometry; Visual science; Pharmacology and drug therapy in eye diseases; Basic Sciences; Primary and Secondary eye care; Patient Safety and Quality of Care Improvements. This journal is indexed on PubMed Central and CAS, and is the official journal of The Society of Clinical Ophthalmology (SCO). The manuscript management system is completely online and includes a very quick and fair peer-review system, which is all easy to use. Visit http://www. dovepress.com/testimonials.php to read real quotes from published authors. 